\title{
Changing views of man
}

\section{Antony Flew}

THIS slim volume consists of five of the six 1976 Herbert Spencer Lectures, a paragraph of Preface, and an Index. There are five only because the sixth lecturer, whom the Editor does not scruple to name, produced no script. No information about the contributors is provided, and there are more misprints - none of these sensedestroying - than one expects under the Oxford imprint. The Editor does not quote the terms of reference under which the lecturers worked. But, speaking presumably for the electors, he does say: ". . . we have gathered together a group of distinguished men from different disciplines to tell us how current work in their own subjects is changing their views of man".

The first essay, by Amartya Sen, is "Rational fools: a critique of the behavioural foundations of economic theory". The target in Sen's sights is that theoretical fiction, economic man; who is, by definition, "actuated only by selfinterest"' (page 1). But he seems not fully to appreciate how drastically this fiction is itself changed if you then proceed "to define a person's interests in such a way that no matter what he does he can be seen to be furthering his own interests in every isolated act of choice" (page 5). For a person who is thus necessarily in every choice striving - as the economists say to maximise his own utilities may well be in the everyday sense - acting very disinterestedly. What Sen explores is the huge area in which actual behaviour, though necessarily maximising the agent's utilities, is by no means reducible to the pure pursuit of that agent's self interest, as ordinarily construed.

In "Psychology and the image of man", Jerome Bruner confesses that in working on his lecture he was "drawn to a disturbing conclusion on the matter of why experimental or academic psychology had not had more of an impact on the broad cultural conception of the nature of man .. ." (page 27). I now confess that, having read the resulting lecture, I am more than ever inclined to think that the reason is that it has had nothing to say that should be of general interest: the genuine discoveries have no wider implications; while the claims which do have a shattering impact are not supported by the empirical work. Skinner, for instance, denies the reality of human choice and human purpose. But these claims are what he mistakes to be presuppositions of any science of psychology. They neither are nor could be
Scientific Models and Man: The Herbert Spencer Lectures, 1976. Edited by Henry Harris. Pp.102. (Oxford University Press/ Clarendon: Oxford, 1979.) £5.95.

findings of his own studies of rats and pigeons.

In "Memory and its models" J.Z. Young writes: "The concept that the brain contains information in a code is the new scientific model of memory, which I believe is revolutionising our view of man" (page 45). I am thus startled to be made to feel that I have all my life been a child of the revolution. For I cannot recall ever believing that information is stored in the brain in the form in which it is remembered. How could it be?

"Machine models of perceptual and intellectual skills" by Donald McKie is fascinating stuff: "The world has a false belief about calculating prodigies, namely that they calculate prodigiously" (page 74). The truth is, apparently, that they use all manner of calculation-saving dodges. The same is true of chess-masters: they neither do nor could work through every thinkable alternative many moves ahead. To achieve a Grandmaster level of play by a computer program on these lines: "It would ... take of the order of $10^{90}$ years' continuous running on a super-fast machine to select a move"' (page 77). For the benefit of possible philosopher-readers

\section{Crossbridge theory in the dock}

\section{R.M. Simmons}

The Molecular Basis of Force Development in Muscle. Edited by N.B. Ingels. Pp. 162. (Palo Alto Medical Research Foundation: Palo Alto, California, 1979.) \$17.

THE sliding filament theory of muscular contraction is generally accepted as well established. Less certain is the mechanism of force generation and shortening, but the great majority of workers in the field accept some form of crossbridge mechanism at the very least as a working hypothesis. There are dissidents from the majority view. This book, the proceedings of a conference held in Miami in 1977 , is edited by one of them and the of Nature I have to mention the suggestive treatment of the seventeenth-century Problem of Dr Molyneux: "R.L. Gregory studied just such a case, in which the patient had had sight conferred on him by an operation of corneal grafting"' (page 62).

In excellent taste, the most exciting contribution is kept till last. In "The universe as artefact"', D.H. Wilkinson ponders Einstein's homespun question: "What does a fish know about the water in which he swims all his life?"' (page 80). Wilkinson's ponderings raise questions about ways in which the basic facts about our nature - size, length of life-cycle, and so on - must eventually limit our possible physical knowledge: ". . . already in the big sciences it takes typically 5 years from inception to completion of an experiment .... When we get to 100 -year long experiments which have to be passed from academic father to academic son we shall not have many takers . . "' (page 82). But I wish that Wilkinson had ended, not by first mentioning and then repudiating Berkeleyan idealism, but with his earlier words: "Perhaps the impossibility of finding quarks is Nature's way of letting us know that we have reached the end of the line.' But we know that we could not accept that."' (page 97).

Antony Flew is Professor of Philosophy in the University of Reading, UK.

conference evidently served as a platform for the views of another (Pollack). Perhaps court-room would be more appropriate than platform, for Pollack seizes the roles of prosecutor, judge, jury and would-be executioner, with orthodoxy embodied by H.E. Huxley, Podolsky, Weber and Julian in the dock.

The trial opens with short pleas from the defendants. The case is nicely argued on the grounds of structure (Huxley and Podolsky), biochemistry (Weber) and mechanics (Julian and Podolsky). The prosecution case from Pollack, subsequently enlarged on in a lengthy cross-examination of the defendants, involves two main charges. The first is that the constancy of filament length demanded by the sliding filament theory is not always to be found in the literature, but Pollack's attempt to weigh the evidence by number of pages rather than by scientific merit becomes more of a trial of patience than of fact. Huxley defends the case as 